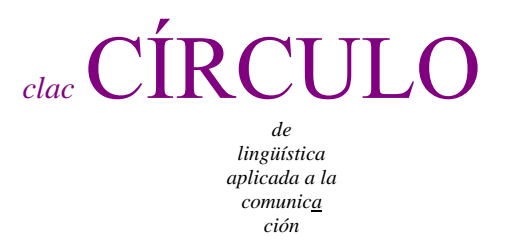

$56 / 2013$

\title{
NUEVAS DINÁMICAS DISCURSIVAS \\ EN LA COMUNICACIÓN POLÍTICA EN TWITTER
}

\author{
Ana Mancera Rueda y Ana Pano Alamán \\ Universidad de Sevilla y Università di Bologna \\ anamancera en us es ana pano en unibo it
}

\section{Resumen}

En este artículo se presentan los principales resultados de un análisis llevado a cabo por las autoras, en torno al discurso político en la red de microblogging Twitter. El objetivo principal de esta investigación, basada en la metodología del análisis lingüístico del discurso, era comprobar de qué manera dispositivos comunicativos como el retuit o el uso de etiquetas o hashtag producen cambios en las estrategias discursivas adoptadas por la política para comunicarse con los ciudadanos en el contexto de la campaña electoral. Para ello, se ha analizado el uso de estos dispositivos en 250 tuits publicados tanto por los principales candidatos a la presidencia del Gobierno de España durante la campaña electoral de 2011, como por sus potenciales votantes.

Palabras clave: análisis del discurso político, comunicación mediada por ordenador, Twitter, red social

Mancera Rueda Ana, y Ana Pano Alamán. 2013.

Nuevas dinámicas discursivas en la comunicación política en Twitter Círculo de Lingüística Aplicada a la Comunicación 56, 53-80.

http://www.ucm.es/info/circulo/no56/mancera.pdf http://revistas.ucm.es/index.php/CLAC

DOI: http://dx.doi.org10.5209/rev_CLAC.2013.v56.43867

(C) 2013 Ana Mancera Rueda y Ana Pano Alamán

Círculo de Lingüística Aplicada a la Comunicación (clac)

Universidad Complutense de Madrid. ISSN 1576-4737. http://www.ucm.es/info/circulo 


\begin{abstract}
New discourse dynamics in Twitter political communication. This paper presents the results of a research carried out by the authors about political discourse on the microblog Twitter. The aim of this work, based on the methodology of linguistic analysis of discourse, was to see how different communicative devices within Twitter such as the retweet of messages or the use of hashtags change the discursive strategies adopted by politicians to communicate with citizens. We have analysed these practices in a number of 250 tweets published by the leading candidates for the presidency of the Spanish government in November 2011, as well as in the messages sent by citizens during the same period.
\end{abstract}

Key words: political discourse analysis, computer-mediated communication, Twitter, social network

Índice

Resumen 53

Abstract 54

1. La irrupción de Twitter en las campañas electorales 55

2. Dispositivos para comunicar en Twitter 57

3. Dinámicas discursivas de los políticos en Twitter 60

3.1. Uso de etiquetas o hashtag 62

3.2. Retuits y menciones 66

4. Unirse a la conversación 70

5. A modo de conclusión 77

Bibliografía 79 
1. La irrupción de Twitter en las campañas electorales

"Esta campaña nunca ha sido sobre mí, sino sobre vosotros", afirmó Barack Obama tras aceptar la nominación que le permitiría concurrir como candidato del Partido Demócrata a las elecciones presidenciales de 2008, en Estados Unidos. Y es que ya desde las primarias, el equipo del senador de Illinois comenzó a "tejer" toda una red de personas para que estas se movilizaran con la finalidad de lograr su voto. Para ello fue involucrando a los ciudadanos de manera individual, lo que le permitió diseñar una campaña de las que en comunicación política se denominan "de fuente abierta", open source, y de persona a persona, peer to peer, "desarrollando relaciones con cada uno de ellos, facilitando la relación de todos ellos entre sí y promoviendo la relación de todos con las personas de su alrededor, los futuros votantes” (Rubio Núñez 2009: 136). Esto fue posible gracias a un uso muy fructífero de tecnologías emergentes como YouTube, Facebook o Twitter. Por ejemplo, Obama seguía a través de su perfil de Twitter a otras 168.000 cuentas. Es decir, seguía casi al mismo número de personas que leía sus mensajes, un detalle de reciprocidad con el que se lograba transmitir "una sensación de proximidad y de igualdad, que en la red, es posible y altamente valorada" (GutiérrezRubí 2008).

De hecho, ninguno de los mensajes enviados por los ciudadanos a los gestores de la campaña en cualquiera de sus plataformas quedaba sin responder. A veces se encargaba de ello el propio Obama, otras Michelle, su mujer, o incluso Hillary Clinton, pero sobre todo lo hacían sus asesores de campaña, ayudados por una gran cantidad de voluntarios. La atención personalizada fue uno de los grandes logros de esta estrategia de comunicación diseñada para hacer que el ciudadano se sintiera escuchado, para hacer que se sintiera especial. A ello contribuyó también el envío de mensajes no intrusivos y redactados en tono personal, que apelaban directamente a cada elector para instarle a la acción o solicitar su voto, pero con una apariencia muy diferente de la propaganda al uso. Gracias a ello daba la impresión de que Obama no hacía publicidad, sino que “dialogaba" con sus electores potenciales.

Casi cuatro años después, los partidos políticos españoles comenzaron a tomar conciencia de que el éxito de la "estrategia de los cincuenta estados" que había otorgado la victoria a los demócratas norteamericanos en 2008 radicaba no tanto en el uso 
indiscriminado de las nuevas tecnologías, como en la participación junto a los ciudadanos en el uso de las redes sociales. El comité electoral del PSOE llegó incluso a contratar al equipo de asesores de Obama, que se desplazó a Madrid para transmitirle enseñanzas aplicables a la campaña electoral española que iba a desarrollarse pocos meses después, en noviembre de 2011.

A raíz de los comicios del $20-\mathrm{N}$, casi todos los candidatos de los principales partidos políticos españoles con representación parlamentaria se percataron de la importancia de la red de microblogging Twitter como plataforma de conexión con los ciudadanos, y abrieron una cuenta personal en ella. Sin embargo, según un estudio elaborado por la agencia de comunicación Applee Tree Communications (2011: 3), “en la mayoría de los casos el uso de Twitter [fue] claramente electoralista", ya que los perfiles se abrieron expresamente para la campaña. Y es que durante los meses previos a la cita electoral, las cuentas de los candidatos más importantes experimentaron un notable crecimiento en el número de seguidores. Aunque, de hecho, existe una gran diferencia entre la acogida recibida por los perfiles de los dos principales partidos y la de las demás formaciones políticas. Así, a lo largo del periodo de campaña, tanto el líder del PP como el del PSOE lograron superar los 60.000 seguidores, mientras que los representantes del resto de las agrupaciones apenas alcanzaron los 20.000. En definitiva, el bipartidismo también pareció triunfar en esta red social.

Para ser exactos, cabe decir que los verdaderamente activos en Twitter no fueron los líderes políticos, sino sus equipos. Por ejemplo, Ángeles Álvarez, la coordinadora de movilización del PSOE durante la campaña electoral, explicaba en una entrevista ${ }^{1}$ que el perfil@conRubalcaba lo actualizaban diariamente tres personas repartidas en tres turnos de ocho de la mañana a once de la noche. Por tanto, el perfil del candidato socialista no podía considerarse personal, aunque llevara su nombre. Durante la campaña, tanto Pérez Rubalcaba como Rajoy delegaron completamente en sus equipos el uso de las redes sociales y las nuevas tecnologías. Así, de los alrededor de 80 tuits diarios publicados en sus respectivos perfiles, menos del 5\% habían sido escritos por ellos mismos. Estos podían distinguirse del resto por las iniciales MR,

\footnotetext{
1 "Entrevista con el equipo 2.0 de Alfredo P. Rubalcaba: 'El Twitter de Rubalcaba es el perfil de su mensaje", PrComunicación, 01-11-2011. Disponible en:

http://www.prnoticias.com/index.php/comunicacion/131/20109976-el-twitter-de-rubalcaba-es-el-perfilde-su-mensaje. Última consulta: 20-05-2013.
} 
Rajoy Brey, Mariano (@marianorajoy). “Agradezco vuest. felicitaciones y muestras de apoyo. Ahora trabajando intensamente en ntro. objetivo: crear empleo y luchar contra la crisis. MR”. 24-11-2011. Tuit. $^{2}$

o RbCb, las firmas que los identifican en Twitter:

Pérez Rubalcaba, Alfredo (@conRubalcaba). “Gracias a todos. He aprendido mucho con vuestras ideas en Twitter. Volvemos a hablar al cerrar las urnas.Vota por tus derechos. RbCb". 18-11-2011. Tuit.

En cambio, en el caso de los candidatos de los partidos minoritarios, fueron estos últimos quienes redactaron la mayor parte de los tuits que conformaban su perfil personal. De hecho, Rosa Díez actualizaba ella misma su cuenta en Facebook, y lo mismo hacía Cayo Lara, quien redactaba todos los días una media de cuatro tuits.

Durante el periodo electoral, los políticos se sirvieron de sus perfiles para dar cuenta de las actividades diarias de la campaña, es decir, para explicar dónde se encontraban, hacia dónde se dirigían, con quién se reunían, etc. Pero, además, recurrían a Twitter para explicar su programa a aquellos votantes potenciales que les seguían a través de esta red social, o para formular nuevas propuestas, sabiendo que entre sus seguidores había también periodistas capaces de convertir un simple tuit en un titular.

\section{Dispositivos para comunicar en Twitter}

Twitter es una plataforma de microblogging o nanoblogging, es decir, un servicio en línea que permite publicar mensajes de no más de 140 caracteres, desde sitios web, a través de SMS, mensajería instantánea o de aplicaciones creadas específicamente para teléfonos móviles. De forma similar a redes sociales como Facebook o LinkedIn, el usuario crea un perfil que suele actualizar regularmente por medio del envío de mensajes breves. La interfaz de Twitter es bastante sencilla. El espacio de una cuenta o perfil está dividido en dos bloques debajo de un menú con las pestañas Inicio, Conecta, Descubre, un buscador y un icono que invita a escribir un mensaje. En el bloque de la

\footnotetext{
${ }^{2}$ Seguimos el formato propuesto por la Modern Language Association (MLA) para la citación de tuits. Además, reproducimos todos los tuits tal y como fueron publicados, sin omitir los errores ortográficos ni aquellas otras muestras representativas del subcódigo escrito que está difundiéndose en Internet.
} 
izquierda aparecen el nombre, la imagen, la biografía y algunos datos -tuits enviados, siguiendo y seguidores- asociados al perfil, una serie de perfiles afines y los Temas globales -también llamados Trending topics-. En el bloque de la derecha, denominado Cronología o Timeline, se publican los tuits que van llegando en secuencia y en orden anticronológico, de más reciente a más antiguo, con la indicación de los segundos, minutos, hora y día de publicación. Los mensajes se muestran públicamente en el perfil del usuario y en la cronología de sus seguidores. El usuario puede restringir el envío de sus tuits a determinados miembros de su círculo de seguidores, o bien permitir su acceso a todos los usuarios que le siguen.

A medio camino entre la bitácora y la red social, Twitter ha generado un código comunicativo y unas pautas de interacción específicas. Así, abandona la reciprocidad obligatoria entre perfiles y cuentas, típica de otras redes sociales, y se erige en un espacio público en el que los mensajes pueden consultarse libremente sin necesidad de invitar a otros usuarios o aceptar invitaciones para que se establezca una conexión. Twitter muestra por tanto un bajo nivel de reciprocidad, aunque estimula el contacto entre personas similares que comparten los mismos intereses, esto es, la homofilia (Murthy 2011). Y es que las conexiones en Twitter son directas y se basan en la práctica del "seguimiento", los usuarios pueden hacer clic sobre el botón Sigue de un determinado perfil de usuario para visualizar los tuits de esa persona, institución o empresa. No obstante, no es obligatorio que ese usuario deba seguir a quien le sigue en la red. Otra diferencia entre las redes sociales y el servicio de microblogging Twitter reside en la distinta función que desempeña, y en las motivaciones que llevan a los internautas a utilizar una u otra aplicación. En las redes sociales es más importante el fin interpersonal, ya que su función es enfatizar la sociabilidad, el contacto y la intimidad continuados. En la red de microblogging, en cambio, lo que se pretende es más bien informar, informarse y opinar sobre cualquier tema compartido por los usuarios que se siguen, generalmente entidades públicas y privadas, celebridades y expertos en todo tipo de cuestiones que, en ocasiones, se erigen en líderes de opinión (Mancera Rueda y Pano Alamán 2013).

Para ahorrar espacio cuando se escribe un tuit, es aconsejable el uso de un lenguaje sintético y claro, el empleo de enlaces acortados y de etiquetas explícitas que relacionen el mensaje que se envía con un tema específico. Así, para escribir textos breves en clac 56/2013, 53-80 
Twitter se han ido adoptando una serie de convenciones que permiten ahorrar tiempo y espacio, y hacer más eficaz la comunicación. Se trata sobre todo de abreviaturas como $\mathrm{RT}$, que corresponde al retuit o reenvío de un mensaje, y DM o mensaje directo, para indicar que se ha enviado un mensaje a un destinatario específico. También se utiliza el signo@, que hace referencia al clásico “a la atención de”, y que permite indicar el destinatario de un mensaje, o mencionar a una persona como el referente de un determinado tuit. La compañía ha añadido en los últimos años nuevas funciones relacionadas con las acciones de los usuarios, así, por ejemplo, para retuitear un mensaje ya no es necesario incluir la abreviatura RT, sino que basta pasar con el ratón por encima de ese mensaje para que aparezca el botón de Retuit, sobre el que es posible hacer clic y reenviar el mismo texto sin que se produzcan cambios en el original.

A fin de enriquecer el contenido de los tuits, muchos incluyen un enlace que permite acceder desde este canal a espacios web, vídeos e imágenes recomendados por los usuarios que se siguen. No obstante, dado que los enlaces pueden ser muy largos y ocupar muchos caracteres es habitual utilizar "acortadores de URL", programas que permiten generar una dirección web abreviada y única. Otro mecanismo frecuente para enriquecer el contenido de un tuit es el de la inclusión en el mensaje de una etiqueta o hashtag, esto es, el signo \# seguido de una palabra o un sintagma, cuya función es marcar el tema del tuit. Las etiquetas son metadatos explícitos sobre los contenidos que vehicula un tuit, de modo que están integrados en su estructura lingüística (Menna 2012). El tema indicado por la etiqueta puede convertirse en un trending topic, o tema global, si aparece en un número elevado de tuits en un momento determinado.

Todos estos dispositivos desempeñan, además, distintas funciones comunicativas (Lara 2012), como la de reconocimiento, cuando se retuitean los mensajes de otros y se reconoce su autoridad sobre la información que se comparte; dialógica, cuando se busca conversar con alguien insertando "@usuario" en el mensaje, o haciendo clic sobre el botón de respuesta; apelativa, al utilizar ese mismo “@usuario” para llamar la atención de alguien, bien porque lo mencionamos agradeciendo un retuit, bien porque queremos que lea lo que publicamos en nuestra cronología; discursiva, en la medida en que, mediante la incorporación de etiquetas, se facilita la lectura de distintos tuits sobre un mismo tema; organizativa, a través de la inclusión de los tuits en listas de interés; de archivo, cuando se guardan aquellos tuits seleccionados, evitando que desaparezcan en clac 56/2013, 53-80 
el rápido confluir de información de la cronología; y, por último, identitaria, pues en el perfil personal del usuario aparecen fotografías y una breve descripción biográfica que le identifican en la Red. Esto tiene que ver con la "reputación pública" del usuario en cuestión, suma de la imagen que quiere dar, y de la imagen de él que proyectan los demás, en función del número de seguidores que posee. Es este un aspecto fundamental para los políticos que abren perfiles en Twitter, ya que dicho canal les permite interactuar con los ciudadanos y acercarse a ellos, ofreciendo una imagen positiva.

3. Dinámicas discursivas de los políticos en Twitter

Como ya hemos tratado de poner de manifiesto, lo que mejor caracteriza a un tuit es su brevedad en relación con el número limitado de caracteres que debe contener el mensaje, y con el tiempo limitado también de su escritura, publicación y lectura. El sistema de envío de tuits se inspira en el servicio de SMS y, por tanto, la instantaneidad y brevedad de los mensajes resultan características esenciales. Por este motivo, en una campaña electoral, el político está obligado a sintetizar su mensaje en pocas palabras y a hacer un uso adecuado de los dispositivos de respuesta, de mención y de retuit de mensajes ajenos, así como de inserción de etiquetas y enlaces, para poder comunicarse eficazmente con los ciudadanos. A partir del análisis de 250 tuits, observamos que todos los políticos se sirven, con mayor o menor frecuencia, de estas convenciones para dialogar con otros usuarios. En primer lugar, abundan los mensajes breves de respuesta a una pregunta o a un comentario de sus seguidores. Observamos, no obstante, algunas diferencias entre los tuits de los principales candidatos. Por ejemplo, el equipo del candidato popular recurre frecuentemente a las abreviaturas, acrónimos y sintagmas escuetos -presumiblemente para ahorrar espacio-, dando lugar a un discurso telegráfico, en ocasiones excesivamente esquemático y técnico, que puede dificultar la lectura:

Rajoy Brey, Mariano (@marianorajoy). “@damianabejassmr, animamos a los ciudadanos al emprend. En el sector de la programación y en el $q$ sea. Los apoyaremos. \#2díasparaelcambio". 18-11-2011. Tuit. 
Rajoy Brey, Mariano (@marianorajoy). “@salvamartin65,al respecto, 'Ref. fiscal para el crec. y la equidad' y 'Créd. para financiar la recup.' págs.42-44/33-35 ow.ly/7h84I”. 0811-2011. Tuit.

Otro aspecto que cabe destacar es su agradecimiento constante a las preguntas o comentarios que recibe. Este dispositivo acerca los tuits de Rajoy a las cartas y a la formalidad típica del género epistolar entre desconocidos; al mismo tiempo, refuerza la distancia entre locutor e interlocutor. A este propósito, cabe señalar que Rajoy prefiere en todos sus mensajes utilizar la forma de cortesía usted o ustedes tanto para los ciudadanos que le escriben como para sus adversarios políticos, mientras que reserva tú y vosotros para sus correligionarios de partido. Todos estos factores hacen que su discurso sea distante y, en ocasiones, repetitivo:

Rajoy Brey, Mariano (@marianorajoy). “@Diogenes_zgz, en bandeja y a domicilio \#ProgramaPP ow.ly/7h84I Ya nos contará qué le parece. Gracias”. 05-11-2011. Tuit.

Rajoy Brey, Mariano (@marianorajoy). “@DanniGuti, no. Tal y como venimos diciendo, vamos a escuchar la sentencia del TC, a todos, y después tomaremos una decisión. Gracias". 05-11-2011. Tuit.

En cuanto a los mensajes de Pérez Rubalcaba, cabe destacar su uso, más o menos recurrente, del registro coloquial, con el que busca acercarse a los ciudadanos. De entrada, tutea tanto a sus seguidores -a la mayoría de los cuales cabe suponer que desconoce-, como a sus compañeros de partido y a sus adversarios políticos, en concreto, a algunos miembros del PP. Como muestra de esa coloquialidad señalamos también la abundante parataxis; el uso de elementos ortográficos que permiten oralizar la escritura, como el alargamiento de vocales, normalmente con una función atenuativa; el empleo de puntos suspensivos, que reproducen la entonación dejando suspendido el enunciado; o el uso de onomatopeyas para imitar la risa:

Pérez Rubalcaba, Alfredo (@conRubalcaba).“@dieGodinamoides estoooo...no sabemos de qué nos hablas ;-)". 09-11-2011. Tuit.

Pérez Rubalcaba, Alfredo (@conRubalcaba). “@anderinaki bueeeeno,nos adulas....por dónde vendrá el palo? Jajaja Por cierto,¿alguna propuesta para \#undebatedecisivo?”. 0711-2011. Tuit. 
También es frecuente en el caso del candidato socialista el uso de emoticonos típicos del discurso en la Red, que permiten expresar estados de ánimo, y modalizar el enunciado imitando las expresiones faciales.

No obstante estas diferencias, debemos señalar que ambos candidatos presentan un estilo similar, de carácter más formal, cuando los tuits constituyen respuestas a comentarios o preguntas que pueden poner en aprietos la imagen del candidato, o cuando deben meditar las respuestas para no dar pie a contradicciones o malentendidos. Por el contrario, adoptan un registro coloquial al hablar de sí mismos, del partido, de la campaña o de los mítines, lo que podría interpretarse como un intento de apelar a las emociones, y de acercarse a sus simpatizantes y a los potenciales electores. En este caso, los tuits de Rajoy abandonan el estilo habitual por un registro más cercano que no renuncia, por ejemplo, al uso de emoticonos o al tuteo:

Rajoy Brey, Mariano (@marianorajoy).“@JAMonago@jotazafra, se nos ha adelantado nuestro querido Presidente extremeño ;) Más preguntas, José Ángel? gracias por su interés". 14-11-2011. Tuit.

Rajoy Brey, Mariano (@marianorajoy). “Entrevista en@A3Noticias a las 21:00 horas. ¡No te la pierdas! \#RajoyA3”. 09-11-2011. Tuit.

\subsection{Uso de etiquetas o hashtag}

Además de los rasgos que acabamos de mencionar, hemos observado un empleo recurrente por parte de los políticos, de los dispositivos propios del canal. Así, durante la campaña electoral de 2011, los principales candidatos incluyeron diversas etiquetas o hashtag por medio de la almohadilla \#, seguida de una palabra o un sintagma cuyas lexías se presentaban fusionadas ${ }^{3}$. Por ejemplo, a raíz de la celebración del cara a cara entre Pérez Rubalcaba y Rajoy el 7 de noviembre, muchos usuarios decidieron insertar la etiqueta \#undebatedecisivo en sus mensajes, para expresar su opinión sobre dicho

\footnotetext{
${ }^{3}$ El equipo de Pérez Rubalcaba utilizó un total de 105 etiquetas frente a las 43 empleadas por el de Rajoy, de acuerdo con el cómputo que hemos llevado a cabo sobre el conjunto de los 250 tuits recogidos. 
encuentro. Por ejemplo, en el siguiente tuit, la etiqueta se presenta precedida de un enunciado interrogativo. Por medio de esta pregunta, que podemos considerar retórica y cargada de ironía, el hablante da a entender que los dos partidos mayoritarios son prácticamente idénticos, de lo cual se puede inferir que gane quien gane el resultado será el mismo, y que por tanto el debate entre ambos candidatos dista mucho de ser decisivo:

fred_SSC (@fred_SSC). “ivosotros quién creéis que va a ganar el debate de hoy, el 'frente judaico popular' o el 'frente popular de judea'? \#undebatedecisivo". 7-11-11. Tuit.

La etiqueta \#undebatedecisivo - hashtag ideado para la red de microblogging Twitter por el equipo del candidato socialista- nació con la pretensión de convertirse en uno de los trending topic más comentados en España, de cara a convencer a los electores indecisos a votar en estas elecciones. Sin embargo, aunque la etiqueta alcanzó gran relevancia, llegando a ser tema global, de hecho provocó una miríada de opiniones críticas con toda la clase política. Como hemos podido comprobar en el ejemplo precedente, la mayor parte de los mensajes que incluía dicha etiqueta denotaba la indiferencia de los internautas hacia el debate, y hacia sus posibles resultados de cara a los comicios. Como apuntaba Rendón en un artículo del 7 de noviembre ${ }^{4}$, la etiqueta acabó siendo empleada por numerosos usuarios precisamente para poner en duda el carácter decisivo del encuentro y para mostrar la naturaleza exclusiva y excluyente del mismo, puesto que solo contemplaba la participación de los candidatos de los dos partidos mayoritarios, como se deduce de estos tuits:

Rodríguez, Olga (@olgarodriguezfr).“Si la televisión pública la pagamos tod@s, ¿por qué sólo se invita a los representantes políticos mayoritarios? \#undebatedecisivo". 07-112011. Tuit.

AndronautA (@AndronautA).“@conRubalcaba \#undebatedecisivo no os pertenece! El debate está en las plazas y en la calle!”. 07-11-2011. Tuit.

En el mensaje dirigido a Pérez Rubalcaba, la etiqueta aparece al inicio del tuit a modo de sujeto del enunciado aseverativo negativo "no os pertenece", de manera que el

\footnotetext{
4 "Twitter desmonta la estrategia del PSOE para el debate", El Semanal Digital, 7-11-2011. Disponible en: http://www.elsemanaldigital.com/blog.asp?idarticulo=117963\&cod_aut=. Última consulta: 02-062013.
} 
hablante no solo sitúa su mensaje entre todos los que contienen ese hashtag, sino que además argumenta contra la exclusión de los ciudadanos de un debate del que los principales partidos parecen haberse apropiado.

Hemos dicho que una etiqueta puede llegar a convertirse en trending topic cuando pasa a ser uno de los temas más seguidos por los usuarios de Twitter en un determinado periodo de tiempo. En el caso que nos ocupa, el del discurso de los políticos durante la campaña electoral, etiquetas como \#stoPP o \#súmatealcambio llegaron a ser trending topic cuando, como eslóganes y consignas, fueron lanzadas por los partidos animando a sus seguidores a utilizarlas en sus tuits. Esto permitía, por un lado, promover una determinada idea, acción o evento relacionados con el propio partido, apelando a las emociones de los propios seguidores. Por otro lado, favorecía el aumento de la visibilidad del candidato y de su partido en esta red social. La difusión viral de estas etiquetas hizo que se convirtieran en los temas más seguidos del momento, alcanzando esos dos objetivos. Aunque, como decíamos, a menudo se obtenía el efecto contrario, pues los ciudadanos las utilizaban más bien para criticar a esos mismos partidos, a juzgar por mensajes como este:

Dejuan, Fede (@fede_dejuan). “Cómo puede haber un haghstag que sea \#undebatedecisivo Decisivo de qué?? Amos no me jodas. Decisivos son los 7 años de desastre". 07-11-2011. Tuit.

En cualquier caso, es posible afirmar que el hecho de que \#undebatedecisivo se convirtiera en tema global respondía a una gran expectativa en torno a los resultados del debate entre PP y PSOE, y ello para satisfacción de los propios candidatos. Esto implicaba un esfuerzo mayor por parte de sus equipos en el seguimiento y recopilación de los tuits relacionados con el tema, como puede presumirse del siguiente tuit enviado desde el perfil de Pérez Rubalcaba:

Pérez Rubalcaba, Alfredo (@conRubalcaba).“\#undebatedecisivo es TT hace rato¿Cómo no serlo con los 5.000 tweets recibidos desde anoche?Alfredo encantado.Los que los recopilamos,no :-P”. 07-11-2011. Tuit.

En este mensaje se afirma que la etiqueta - sujeto de la primera oración- se ha convertido en TT, acto asertivo al que le sigue uno interrogativo retórico, que constituye 
la segunda oración, con el que se justifica que lo sea (“¿cómo no serlo?”); a continuación, el equipo informa de la reacción positiva del candidato al haber recibido 5.000 mensajes en pocas horas, mientras que el último enunciado contrapone esa postura a la reacción negativa de quienes los recopilan. Del adverbio de negación final se infiere que "no estamos encantados de haber recibido 5.000 tuits", pero el desánimo se atenúa al final gracias a un emoticono que imita el gesto de sacar la lengua, y que sirve al equipo para decir que no hay que tomar en serio lo dicho. Por tanto, podemos encontrar en este tipo de tuits, remitidos por el equipo de uno de los candidatos, notables dosis de ironía.

Las palabras contenidas en la etiqueta marcan el tema del tuit, e invitan a otros usuarios a adoptar esa misma etiqueta para indicar el contenido de sus mensajes, y a sumarse a otras intervenciones sobre ese mismo asunto. De hecho, la presencia de la almohadilla expande el significado potencial del tuit, pues no solo identifica su contenido, sino que, además, permite recuperarlo después por parte de quien suscribe esa misma etiqueta, consintiendo así "tejer conversaciones alrededor de un tema determinado e incluso entrar espontáneamente en conversaciones ajenas con el simple uso de su misma palabra clave" (Lara 2012). En este sentido, es posible afirmar que el uso de etiquetas favorece la polifonía, ya que la adopción de esa palabra o palabras clave por parte de una comunidad de personas interesadas en ese tema vehicula distintas voces en torno al mismo. La almohadilla también promueve lo que Zappavigna (2011) denomina un "ambiente de afiliciación", en referencia a que los usuarios se unan temporalmente a una comunidad compartiendo sus puntos de vista sobre un tema que evoluciona en el tiempo. Esto resulta especialmente relevante en las campañas electorales, pues el uso colectivo de ese tema por parte, tanto de los simpatizantes como de los adversarios de uno u otro candidato, puede dar lugar a discursos muy heterogéneos en un mismo espacio comunicativo, el de la cronología asociada al tema en cuestión. 


\subsection{Retuits y menciones}

Como apuntábamos en relación con el carácter no recíproco de esta red, en Twitter no se espera que nuestro mensaje sea contestado, o que debamos contestar a otro mensaje. Sin embargo, entre los usuarios sí parece existir la necesidad de conectarse con otras voces en público y en privado. En este sentido, cabe señalar que este tipo de internautas hace un uso creativo de la puntuación para establecer tales "conversaciones" con otros. Así, además del uso del hashtag, otros dos dispositivos que favorecen la conexión son la mención (@), con función apelativa y dialógica, y el retuiteo (RT), cuya función es la de cita.

En primer lugar, la mención se relaciona con el signo de la arroba @, que se utiliza como marcador deíctico: funciona como vocativo, como forma de dirigirse a alguien, pero también para indicar la fuente de una información. Se trata de un mecanismo discursivo fundamental en este medio puesto que, como señala Yus (2010: 165), de entre todas las actividades inferenciales que necesita llevar a cabo el lector de un tuit destaca la de la "asignación de referente" respecto al emisor y el destinatario del mensaje. Por ejemplo, a este mensaje de Pérez Rubalcaba, en el que su equipo ha tuiteado las palabras pronunciadas por el candidato durante un mitin en Valencia,

Pérez Rubalcaba, Alfredo (@conRubalcaba). “'Hay dos modelos para salir de la crisis.El objetivo de nuestra política son las personas.' Gracias! \#ValenciaconRbCb \#Peleaporloquequieres". 06-11-2011. Tuit.

responde uno de sus seguidores insertando la arroba al inicio del tuit tras el nombre que identifica al perfil del político, seguido de una interjección reduplicada que simboliza el aplauso respecto a lo dicho por el candidato socialista, reforzando el acuerdo hacia lo asertado por este:

Martínez, Carina (@Karem1976).“@conRubalcaba ole,ole y ole...ojala suceda, sois lo que este pais necesita”. 06-11-2011. Tuit.

Y en este otro mensaje, el nombre del perfil del político precedido por la arroba funciona a modo de vocativo: 
Haro, Juan (@Molibdor). “@conRubalcaba Pues hasta ahora el @PSOE no ha demostrado que las personas sean el objetivo (a no ser que sea para captar votos!) \#NoLesVotes". 06-11-2011. Tuit.

Sin embargo, a este le sigue un pues, marcador discursivo estructurador de la información que suele preceder a intervenciones reactivas ${ }^{5}$. En este tuit resuenan las propias palabras de Pérez Rubalcaba, en concreto, su referencia a las "personas" como “objetivo" central de la política del PSOE, palabras que el hablante retoma para enfatizar su desacuerdo con el candidato y poner en evidencia su uso electoralista, concluyendo que es mejor no votar a este partido, acto exhortativo expresado mediante la etiqueta \#NoLes Votes.

Elsigno@ no solo indica quién es el destinatario de una respuesta, sino que permite también identificar a otro usuario como fuente de información. Es este un acto que podríamos calificar de cortés, dado que la atribución de un mensaje favorece a la reputación, es decir, a la imagen positiva de su autor, como se observa en el tuit de contestación de Pérez Rubalcaba al siguiente mensaje,

Joaquín (@lao_huajin).“@antonigr@conrubalcaba Si tienes reputación en Twitter, tus preguntas valen mas. Me gusta. Es la esencia del SOCIALISMO del @PSOE”. 10-11-11. Tuit.

Pérez Rubalcaba, Alfredo (@conRubalcaba).“@lao_huajin el criterio lo ha marcado@antonigr”.10-11-11. Tuit.

en el que el candidato menciona a @antonigr, reconociendo a este el mérito de haber marcado un criterio de conducta en Twitter que su interlocutor considera positivo. Generalmente, este dispositivo sirve para mencionar a otro usuario afín al propio discurso, insertando su nombre en medio o al final del mensaje:

Mariano Rajoy Brey (@marianorajoy)."Mitin de cierre de campaña con@mdcospedal @EsperanzAguirre @equipogallardon. En directo a las 20.30h. en rajoy.es y en tu app". 18-11-11. Tuit.

Pérez Rubalcaba, Alfredo (@conRubalcaba). “Buenos días. En el despacho preparando con@ElenaValenciano el acto con los voluntarios de esta mañana. RbCb http://pic.twitter.com/swNzmw73". 04-11-2012. Tuit.

\footnotetext{
${ }^{5}$ Así lo ha puesto de manifiesto Briz, entre otros: "Pues presenta, unido a su valor fórico, un papel conversacional como marcador de respuesta, que enfatiza el acuerdo o el desacuerdo" (Briz 1998: 174).
} 
En estos tuits, Pérez Rubalcaba y Rajoy informan a sus seguidores de lo que van a hacer o de lo que están haciendo en ese momento. El mensaje de Rajoy menciona a Cospedal, Aguirre y Gallardón en un tuit sobre el mitin que está a punto de iniciar. En este caso, la mención parece llamar la atención sobre la importancia del encuentro, pues anuncia que contará con la presencia de miembros de altura del PP. Este mecanismo permite también reforzar las relaciones entre el candidato y sus correligionarios. El de Pérez Rubalcaba incluye el nombre de Elena Valenciano en un tuit que pretende presentar al candidato como un político que trabaja en equipo, en concreto, con su coordinadora de campaña y número dos en las listas por Madrid.

Como decíamos, junto a la mención, otra estrategia muy utilizada es la del retuit, por medio de la abreviatura de RT o del botón Retuit, que favorece la polifonía textual (Menna 2011: 15-16). La posibilidad de incluir en el discurso un coro de voces que sostienen o rechazan lo que decimos se convierte en una estrategia fundamental en la comunicación política y en la formación de la opinión pública en Twitter, ya que se relaciona directamente con la posibilidad de retomar el discurso de otro, con fines argumentativos y persuasivos. En el siguiente ejemplo,

Pascual, Alberto (@albertpasdice). “Los japoneses crean un chip que puede 'leer' la mente http://bit.ly/s4sATJ @conRubalcaba se ha interesado para el próximo debate con Rajoy" - Retwitteado por Alfredo Pérez Rubalcaba. 09-11-2011. Tuit.

Pérez Rubalcaba retuitea desde su propio perfil un mensaje en el que un internauta especula sobre el interés del candidato socialista por hacerse con un chip que le permita leer la mente de su "adversario" en el debate. El político reenvía este mensaje de @albertpasdice desde su propio perfil manteniendo las referencias deícticas del mensaje original. De este modo otorga valor a un mensaje cuyo tono humorístico considera relevante y positivo para su campaña, y amplifica su efecto, pues contribuye a que el texto circule de forma viral entre sus seguidores.

Este mecanismo ostenta además una clara finalidad persuasiva, como puede apreciarse en este mensaje en el que desde el perfil de UPyD, y por medio de la adaptación del mensaje original, se retuitea el texto publicado por uno de sus seguidores: 
Pas, Alberto (@albertpasdice)."RT @rossoreus: Ahora se que no estoy solo, que hay 1 millón conmigo y con @UPyD”- Retwitteado por UPyD. 09-11-2011. Tuit.

Retuiteando este mensaje -que surge a su vez de otro retuit-, el gestor de la cuenta de UPyD no solo se adhiere a las palabras del autor del mensaje original, sino que lo comparte con sus seguidores, ampliando su esfera de influencia. Se trata de un texto en el que el hablante menciona al partido incluyéndose -e incluyéndolo- en un espacio en el que, supuestamente, distintas personas comparten las posiciones de UPyD. A partir de la constatación "hay 1 millón [de personas/electores] conmigo y con UPyD” deduce que no está solo, que no está en minoría, como podría suponerse en el caso de los seguidores de esta fuerza política frente a los de los partidos mayoritarios. Por medio de la mención al partido (@UPyD), el usuario llama su atención; quienes gestionan esta cuenta reciben notificación de este tuit y retuitean a su vez el mensaje para difundirlo entre sus seguidores. De esta forma agradecen el gesto a @rossoreus y muestran, además, acuerdo con su contenido, pues contribuyen a vehicular la idea de que UPyD no es un partido minoritario, ampliando también su presencia en el canal.

Veamos otro caso, por ejemplo, el de este mensaje en el que Esperanza Aguirre retuitea un texto difundido por el perfil del Partido Popular de Madrid, y anuncia que la etiqueta \#rajoygana se ha convertido en TT, es decir, en trending topic:

Esperanza Aguirre (@EsperanzAguirre)."RT@ppmadrid: \#rajoygana es TT mundial. \#caraacara". 7-11-11. Tuit.

Si bien el retuiteo puede ser visto simplemente como un acto de copia y retransmisión, de hecho esta práctica contribuye a construir una "ecología conversacional” (Boyd, Golder y Lotan, 2010), en la que el intercambio está constituido por una interacción pública de voces que da lugar a una percepción de contexto compartido. Y es que la mención y el retuiteo pueden entenderse como formas de difusión de la información y como medios eficaces para participar en una "conversación extendida". 


\section{Unirse a la conversación}

Hemos hablado aquí de conversación, si bien es necesario matizar este concepto. Como señalábamos más arriba, una de las principales funciones comunicativas que se atribuyen a un tuit es la dialógica, ya que por medio de la mención o indicación de “@nombredeusuario" en el mensaje, o simplemente pulsando el botón de "respuesta", permite interactuar con cualquier persona o entidad que disponga de un perfil en Twitter. En este caso, hemos observado que en el transcurso de la campaña, los políticos dialogaban diariamente con los ciudadanos utilizando la mención como apelación directa. Así, durante los momentos más intensos del período preelectoral, los equipos de redes sociales de los principales candidatos se valieron de este mecanismo para contestar directamente a los usuarios en relación con sus propuestas políticas, siguiendo pautas de estructuración del discurso muy similares, como se observa en estos dos ejemplos:

David Sanchez (@ArcticAcid).“@conRubalcaba quiero que se comprometa con los jovenes como priorida en su agenda, las nuevas generaciones son aun mas que importantes". 16-11-11. Tuit.

Pérez Rubalcaba, Alfredo (@conRubalcaba). “Por supuesto, @ArcticAcid La juventud es apuesta de futuro. Haremos un Plan especifico de Empleo para Jóvenes. Más en rubalcaba.es". 16-11-11. Tuit.

Pilar Blanc Atienza (@Piblanc). “@marianorajoy su programa dice que va a bajar los impuestos, se refiere a bajar los impuestos a rentas altas? al resto de rentas subirlo no?”. 31-10-11. Tuit.

Mariano Rajoy Brey (@marianorajoy).“@Piblanc, en materia de impuestos, reforma fiscal para el crec. y la equidad.Conozca nuestras medidas p.43-44 ow.ly/7h84I". 14-11-11. Tuit.

En estos intercambios constituidos por pares adyacentes de pregunta/respuesta -los más numerosos en nuestro corpus-, el discurso se caracterizó, como decíamos, por un elevado nivel de formalidad, un tono impersonal y una mención frecuente de los programas, a través de enlaces a vídeos y textos relacionados con las propuestas de cada partido. Por el contrario, los ciudadanos se dirigían a los políticos promoviendo la función dialógica de la red de modo más creativo. Por ejemplo, a este tuit de UPyD 
destinado a Martínez Gorriarán y que, gracias al punto que aparece al inicio delante de la arroba, verán todos los seguidores del partido ${ }^{6}$,

UPyD (@UPyD).“.@cmgorriaran: Estas elecciones nos dan la oportunidad de cerrar la Transición bit.ly/u3u7nr \#cadavotovale”. 7-11-11. Tuit.

LIKILACATU (@Likilacatu).“@UPyD@cmgorriaran Una leche, acaba de empezar una revolución. La indignación crecerá con el gobierno del PP, así que UPyD tendrá opciones". 7-11-11. Tuit.

responde un internauta con una apelación directa al partido y al perfil del político en cuestión. Tras la apelación, el hablante inserta el sintagma "una leche", unidad fraseológica que funciona como operador contraargumentativo de rechazo enfático aislado entonacionalmente por medio de la coma, con el que manifiesta de manera intensificada su desacuerdo hacia la aserción de que las elecciones son el mero colofón de la Transición. Esta expresión tiene además una función interactivo-modal, es decir, señala una reacción anímica relacionada con el rechazo de ese acto de habla previo, aparentemente insuficiente para este hablante. Tras él introduce el argumento de que lo que las elecciones constituyen en realidad es el germen de un proceso revolucionario que ya se ha iniciado, y que crecerá motivado por el descontento durante el gobierno del PP, ampliando el margen de acción de UPyD. Otro internauta publica este otro mensaje en el que retoma las últimas palabras del tuit de UPyD, a modo de pregunta ecoica, e introduce un enunciado copulativo cargado de ironía, con el que manifiesta su incredulidad hacia las declaraciones formuladas por Martínez Gorriarán:

Rodríguez, Guillermo (@Guillermo_RT).“@UPyD@cmgorriaran La transición??? Es infinita, o qué?". 07-11-2011. Tuit.

En otra línea argumentativa se sitúa este otro tuit de respuesta al primer mensaje de UPyD,

\footnotetext{
${ }^{6}$ Cuando un usuario de Twitter menciona a otro por medio de @nombredeusuario, únicamente las personas que siguen a ambas cuentas, es decir, los seguidores comunes de quien envía el tuit y de quien es mencionado pueden visualizar el mensaje. El punto delante de la arroba permite que ese mensaje llegue a la cronología de todos los seguidores del emisor, en este caso, a todos los seguidores de UPyD y no solo a quienes siguen al partido y a Martínez Gorriarán por igual. Este dispositivo permite por tanto ampliar el número de destinatarios del mensaje.
} 
Ignacioac(@atlas_tomatoe).“@UPyD@cmgorriaran es q30 años de transición...jmanda huevos! \#cadavotovale”. 07-11-2011. Tuit.

en el que encontramos un enunciado suspendido precedido por el verbo copulativo ser y la conjunción que abreviada, una pauta reveladora de proximidad comunicativa que indirectamente suele asimilarse a las locuciones conjuntivas características de las causales explicativas. Pero en esta ocasión la expresión malsonante que le acompaña deja entrever su carácter de refuerzo de lo asertado previamente, denotando además cierta sorpresa.

Una de las dinámicas discursivas más innovadoras que tuvieron lugar en Twitter durante la campaña, fue la de reproducir en estilo directo o indirecto el propio discurso político, emitido durante el debate cara a cara o durante los mítines, en una suerte de diálogo entre los candidatos que se extendía desde la televisión a la red de microblogging. Por ejemplo, en el transcurso del debate entre Rajoy y Pérez Rubalcaba, el equipo del primero reproducía en estilo directo en su propio perfil, las palabras que este iba diciendo ante las cámaras:

Rajoy, Mariano (@marianorajoy).“"Cómo tiene usted la osadía cuando ha sido vpte del Gobierno que ha dado lugar a que + de $3 \mathrm{~m}$ de personas hayan perdido su empleo?' \#Caraacara". 07-11-2011. Tuit.

Ello suscitó cierto estupor entre sus seguidores, que le increparon para que se centrara más en el debate,

Leis Paula (@Pau_314).“@marianorajoy deja de tuitear y atiende al debate!”.07-112011. Tuit.

y bromearon con su capacidad para debatir y escribir mensajes al mismo tiempo:

Guten (@Guten_DOC). “@marianorajoy como puedes tuitear y estar debatiendo a la vez? ahora si que te voto crack ...ee.. NO”. 07-11-2011. Tuit.

Véase cómo, en este último mensaje, el internauta hace mención del perfil de Rajoy, al que increpa directamente mediante una pregunta retórica con notables dosis de ironía para, a continuación, sustituir la segunda persona por un enunciado en primera persona 
con el que anuncia su intención de votarle. Llama la atención aquí el uso que se hace del apelativo "crack", que creemos que en este caso podría englobarse entre los denominados por Cortés y Camacho (2005) como "marcadores interactivos centrados en el oyente". Pero enseguida parece arrepentirse de su anuncio de votar al candidato popular, por lo que introduce el adverbio de negación, con el que pretende reformular su aserción previa.

El análisis llevado a cabo sobre los tuits recogidos durante la campaña electoral nos permite afirmar que, en lo que al discurso político se refiere, estamos ante dos manifestaciones distintas de "conversación". Por una parte, la del intercambio dialógico propiamente dicho, con un turno iniciativo y uno reactivo, de uno a uno, cuando un ciudadano pregunta a un político y este responde, o cuando el ciudadano comenta lo que el político acaba de decir. En este caso, son habituales en nuestro corpus secuencias como esta,

UPyD (@UPyD). "Rosa Díez sobre el debate: "Cuesta 540.000 €. Y todo, ¿para ver quién es más guapo?" bit.ly/vyyaBK \#cadavotovale". 07-11-2011. Tuit. respuestas $\downarrow$

Menchu (@ASTURIASMALENA) “@UPyD jajaj ninguno de los dos el que es guapo\#elseñortonycanto un abrazo y adelante a por ellos”. 07-11-2011. Tuit.

Bonet, Nur (@guatanericonsu).“@UPyD no, para ver quién es peor”. 07-11-2011. Tuit.

Julià, Lupe (@AnamKra).“@UPyD lo de hoy en@tve_tve NO ES UN DEBATE es una foto fija con discursos repetidos por eso \#cadavotovale". 07-11-2011. Tuit.

Novillo, Alberto (@albertonovillo).“@UPyD entonces va a ganar Manuel Campo Vidal ... ;-)". 07-11-2011. Tuit.

en la que el político publica un mensaje invitando a la reacción de los propios seguidores. Estos envían sus tuits dirigiéndose al político en cuestión, el cual, sin embargo, abandona la “conversación”. Aquí, la intervención iniciativa de @UPyD plantea la cuestión del coste del debate entre los candidatos de las dos principales fuerzas políticas por medio de la cita directa de una pregunta de Rosa Díez. En el mismo tono irónico contestan los ciudadanos, respondiendo directamente a la cuenta del partido mediante la arroba y el nombre de usuario. Casi todas las respuestas van en la 
misma dirección, para decir que el debate tiene un coste excesivo y sobre todo, que será inútil, ya que no representa a todas las opciones electorales.

Como vemos, hay en todos estos mensajes una gran dependencia contextual. Además, la adecuada restitución de la prosodia es clave para interpretar construcciones modalizadoras como estas, más propias de la proximidad comunicativa y del registro coloquial de la lengua. En este tipo de intercambios, en los que los ciudadanos reaccionan a un primer mensaje del político, las interacciones presentan mayor proximidad comunicativa debido sobre todo al carácter a menudo polémico de los tuits, y a la percepción entre los interlocutores de menor distancia entre ellos y los candidatos. La presencia habitual en nuestro corpus de este tipo de secuencias nos permite afirmar también que en Twitter la conversación adopta sobre todo la forma de un discurso colectivo en el que, más que un diálogo entre distintos interlocutores, se da una suma de voces en torno a temas compartidos, que se acumulan dando lugar a una secuencia.

Se ha dicho que el poder de la conversación en Twitter reside en su poder viral, es decir, en su capacidad para canalizar y amplificar la comunicación a niveles nunca antes conseguidos por el sistema analógico del boca a oreja (Parmelee y Bichard 2012: 4-6). El elemento central de este fenómeno reside en la reconfiguración de un público que se ha transformado "abriendo ventanas a la interpretación, negociación y definición de la realidad" (Valeriani 2011: 48). Como hemos visto, este es más bien un espacio en el que muchas voces hablan y se conectan con otras voces en público, mediante un uso creativo de las menciones, etiquetas y retuits, refiriéndose a otros usuarios y marcando los temas que circulan como de interés general para todos. En este sentido, un concepto que permite describir la naturaleza conversacional de Twitter y de otras redes sociales es el de "hilos de escritura". Se trata de "conversaciones multifuente - de varios usuarios- que no necesariamente comparten tiempo ni momento de incorporación y que pueden utilizar varios entornos en una misma charla” (López Sobejano 2012: 170). Entre otras cosas, permiten incorporaciones constantes, ya que es posible que los usuarios entren en una conversación según sus intereses, provocando interrupciones en los hilos argumentativos dominantes y ramificaciones temáticas.

El análisis que hemos llevado a cabo nos lleva a sostener que durante la campaña electoral los políticos se sirvieron de Twitter para lanzar consignas y publicar mensajes destinados a generar distintas reacciones en hilos de escritura que se prolongaban en el clac 56/2013, 53-80 
tiempo. Sin embargo, paradójicamente, rara vez participaron en ellos de forma plena, es decir, interactuando con sus seguidores. En cambio, los ciudadanos sí supieron elaborar discursos colectivos relacionados con consignas, temas o etiquetas que no siempre surgían de la iniciativa de los equipos de campaña. Por ejemplo, durante la jornada electoral del $20-\mathrm{N}$ se publicaron en la red numerosos tuits relacionados con el tema "La Comunidad del Anillo", título de la trilogía de J.R.R. Tolkien y de la película homónima de P. Jackson. El hecho de que la película se emitiera en televisión española esa misma tarde, y de que muchos usuarios la incluyeran en sus mensajes, hizo que el sintagma se convirtiera en trending topic. Como podemos apreciar en los siguientes ejemplos, el sintagma que hemos destacado desempeña distintas funciones en enunciados que se relacionan tanto con la película como con las elecciones, e incluso con las propias dinámicas de la red:

Nacho Arregui (@Naxo767)."Ver La Comunidad del Anillo y darte cuenta que te sabes TODOS los putos dialogos. \#queputofrikisoy". 20-11-2011. Tuit.

Rubén Porto (@RubenPorto87). “Abrir el twitter y encontrarse que La Comunidad del Anillo es TT sí que no tiene precio”. 20-11-2011. Tuit.

Ángela Castañeda (@angela_16_06).“La Comunidad del Anillo es TT por encima de las elecciones! Jajaja, Twitter es la pera... No sabes por dónde va a salir...”. 20-11-2011. Tuit.

Srchinaski (@srchinaski). “Martín, Rober (@RobertMartn).“\#20N, Cristo Rey, Francisco Franco, \#ApoderadosUPyD y La Comunidad del Anillo. Jamás pensé q diria esto pero: te echo d menos, Justin Bieber". 20-11-2011. Tuit.

Estos tuits, aunque comparten el mismo sintagma y parecen sucederse como turnos en una interacción, no presentan una dinámica conversacional, entendida esta como alternancia de turnos inmediata, en la que la relación hablante/oyente es simultánea y cooperativa en relación con la intervención del otro (Briz 1998). En realidad, los ejemplos anteriores constituyen un tipo de discurso colectivo que no puede considerarse en modo alguno una conversación prototípica, pues la mayor parte de los hablantes, al elaborar su propio mensaje, no tiene en cuenta lo que aserta el interlocutor precedente. Cada uno aporta su punto de vista independientemente del tuit que le antecede, y esto se explica por la especial idiosincrasia de Twitter. Recordemos que aquí no existe reciprocidad entre perfiles y cuentas, aunque sí es posible seguir etiquetas o temas 
generados por un sinfín de personas que los integran en sus enunciados. De este modo, los tuits originados en muy distintos perfiles se publican en un mismo espacio sin más relación que el del tema compartido. Podríamos incluso decir que en este caso se da una relación dialógica (Bajtín 1979 [1992]) entre los mensajes que se acumulan, y entre estos y la película, por lo que en el discurso no se oye solamente la voz del emisor, sino que en él convive una pluralidad de voces superpuestas que entablan un diálogo entre sí. Por ello también, en estos mensajes es habitual la cita,

Jose Cosin (@Jose_Cosin). "La comunidad del Anillo: 'Incluso la persona mas insignificante puede cambiar el curso del futuro' \#Soyunfrikazo”. 20-11-2011. Tuit.

la parodia,

A V (@AlveCuteMonster). “\#ARAGORNPRESIDENTE Porque pondría a la comunidad del anillo de diputados, y en españa sobran orcos". 20-11-2011. Tuit.

o la ironía:

cheble (@cheble). "La comunidad del anillo en tve1. Mordor va a ser mas habitable que España en unos meses. Sauron llevame contigo!!! \#DoRiYakiTU \#juntazo". 20-11-2011. Tuit.

En nuestro corpus se observa además una dinámica similar cuando los temas se encuentran relacionados con las elecciones. Por ejemplo, en los tuits que siguen puede apreciarse cómo la etiqueta \#jornadadereflexión generó numerosos enunciados de carácter humorístico que guardan vinculación con la acción misma de reflexionar:

Soy un Click (@tanclick). “Un pasillo lleno de chicas guapas, ¿Es un corredor de apuestas? \#jornadadereflexion”. 20-11-2011. Tuit.

José Enrique Pérez (@jjepgfenix). “¿Si un veneno está caducado es más venenoso o menos venenoso? \#jornadadereflexion”. 20-11-2011. Tuit.

José Enrique Pérez (@jjepgfenix). ¿Los empleados de twitter cierran el excel cuando ven al jefe acercarse? \#jornadadereflexion". 20-11-2011. Tuit.

Se ha dicho que en Twitter, sobre todo cuando se usa con fines políticos, lo importante es "escuchar" y aportar valor, es decir, llevar la iniciativa mencionando nuevos datos y personas, prestando atención a lo que dice la gente -esto es, a los temas del momento-, y aportar allí donde los electores estén participando de forma masiva (Fuguet 2011). clac 56/2013, 53-80 
Aunque, como hemos visto, el número de intercambios de pregunta-respuesta entre los principales candidatos y algunos de sus seguidores es muy alto en el periodo de campaña, se trata generalmente de un diálogo que concierne a lo sumo a dos o tres interlocutores, y que se limita a esos dos turnos. Y es que los políticos, a pesar de que en la mayoría de los casos contestan a los mensajes que les dirigen los ciudadanos en relación con los programas de sus partidos o sus propuestas políticas, rara vez se unen a la conversación.

\section{A modo de conclusión}

La propuesta de análisis de la comunicación política que presentamos aquí parte de una investigación previa (Mancera Rueda y Pano Alamán 2013), que hemos tratado de completar en este artículo sobre las nuevas dinámicas discursivas que pueden identificarse en los intercambios entre políticos y ciudadanos en la red de microblogging Twitter. Así, el estudio de un corpus de 250 tuits nos ha permitido comprobar cómo la mayor parte de los candidatos -por medio de sus equipos- adopta eficazmente las estrategias descritas en relación con el medio. Por ejemplo, estos promueven determinadas etiquetas para ampliar la información sobre un tema y favorecer su extensión de forma viral. También retuitean a menudo, e incluyen enlaces para dirigir a sus seguidores hacia determinadas noticias o datos relacionados con la campaña. No obstante, su uso del microblog está más cerca de las prácticas tradicionales de los medios de comunicación de masas, que de las redes sociales.

La comunicación en este contexto debe basarse en la intertextualidad y la polifonía por medio del uso del vocativo y del apelativo en función de llamada de atención; de la mención como mecanismo de atribución de referente - no solo del otro político, sino también de los seguidores-; del retuiteo, como dispositivo de cita y para crear afiliación con los propios seguidores y con los de estos; de las etiquetas y de los enlaces propios y 
ajenos. Se trata de mecanismos que los políticos españoles utilizan a menudo, aunque, en la mayor parte de los casos solo se refieren a sí mismos o a sus contrincantes, a los partidos y a los programas, que alaban o critican sin salirse del guión. Además, el diálogo entre los candidatos y sus seguidores se limita esencialmente al par preguntarespuesta, donde la respuesta del candidato suele intervenir como turno de cierre en el que no cabe espacio para la discusión. La "conversación" se basa, pues, en un tipo de interacción tradicional, en una comunicación asimétrica y vertical de político a ciudadanos y de ciudadanos a político, que no acaba de adaptarse a las prácticas de los internautas. De modo que los políticos aparentemente dialogan con todos, pero escuchan solo a algunos - políticos o periodistas a lo sumo- y, aunque escuchan, no lo hacen suficientemente.

Así pues, a pesar del esfuerzo de los equipos 2.0 de las principales formaciones políticas por "importar" en la escena electoral española algunas de las estrategias popularizadas por los asesores de Obama, estos no parecieron darse cuenta de que la victoria del candidato de Honolulú fue posible gracias a su capacidad para escuchar las voces de los ciudadanos, que se "sintieron" los verdaderos protagonistas de la campaña. Por primera vez en España, en 2011 la clase política tomó conciencia de la relevancia de las redes sociales virtuales. Sin embargo, hizo de ellas un uso electoralista que ya era habitual en los medios tradicionales. Los denominados discursos mitineros se convirtieron entonces en arengas tuiteras, difusoras de propaganda, sin que los candidatos lograran percatarse de que en realidad lo importante en Twitter es fomentar la polifonía por medio del retuit de mensajes ajenos al partido, y de la mención y el enlace a informaciones que versen sobre lo que realmente preocupa a los ciudadanos. Si se trata de tejer una red de personas a las que trata de movilizarse para lograr su voto, es necesario promover la relación con los futuros votantes por medio de un discurso en el que quepan distintas voces. 


\section{Bibliografía}

Applee Tree Communications (2011). Twitteroscopio \#0.2: edición especial elecciones generales 2011. Disponible en:

http://www.appletreecommunications.com/es/social-media-lab. Última consulta: 02-06-2013.

Bajtín, M. (1979 [1992]). Estética de la creación verbal, México, Siglo XXI.

Boyd, D. M., Golder, S. y G. Lotan (2010). "Tweet tweet retweet: Conversational aspects of retweeting on Twitter", Proceedings of the 43rd Hawaii International Conference on System Sciences. Hawai, HI, IEEE Press. Disponible en: http://csdl.computer.org/dl/proceedings/hicss/2010/3869/00/03-06-04.pdf. Última consulta: 02-06-2013.

Briz Gómez, A. (1998). El español coloquial en la conversación. Esbozo de pragmagramática, Barcelona, Ariel.

Cortés Rodríguez, L. y M. M. Camacho Adarve (2005). Unidades de segmentación y marcadores del discurso: elementos esenciales en el procesamiento discursivo oral, Madrid, Arco Libros.

Fuguet, A. (2011): “Abreviaturas imprescindibles en Twitter”, El Llautó. Disponible en: http://www.albertfuguet.com/2011/09/abreviaturas-imprescindibles-entwitter.html. Última consulta: 02-06-2013.

Gutiérrez-Rubí, A. (2008). "Lecciones de la campaña de Obama”, Revista Fundació Rafael Campalans, 16, pp. 75-82. Disponible en: http://www.fcampalans.cat/uploads/publicacions/pdf/frc17_gutierrezrubi.pdf. Última consulta: 02-06-2013.

Lara, T. (2012). “Twitter y sus funciones comunicativas”, Blog Tíscar.com. Disponible en: http://tiscar.com/2012/03/11/twitter-y-sus-funciones-comunicativas. Última consulta: 02-06-2013. 
López Sobejano, J. (2012). "Redes sociales”, en M. Tascón (dir). Escribir en Internet. Guía para los nuevos medios y las redes sociales, Madrid, Fundéu-BBVA, pp. 151-178.

Mancera Rueda, A. y A. Pano Alamán (2013). El discurso político en Twitter, Barcelona, Anthropos Editorial.

Menna, L. (2012). "Nuevas formas de significación en red: el uso de las \#etiquetas en el movimiento 15M", Estudios de Lingüística del Español, 34. Disponible en: http://elies.rediris.es/elies34/Tesina_L-Menna.pdf. Última consulta: 02-06-2013.

Murthy, D. (2011). “Twitter: Microphone for the masses?”, Media Culture Society, 33 (5), pp. 779-789. Disponible en:

http://www.bowdoin.edu/faculty/d/dmurthy/pdf/twitter-microphone-for-themasses-dhiraj-murthy.pdf. Última consulta: 02-06-2013.

Parmelee, J. H. y S. L. Bichard (2012). Politics and the Twitter Revolution. How Tweets influence the relationship between political leaders and the public, Londres, Lexington Books.

Rubio Núñez, R. (2009). "Quiero ser como Obama (me pido una red social)", Cuadernos de pensamiento político FAES, 21, pp. 123-154.

Valeriani, A. (2011). Twitter Factor. Come i nuovi media cambiano la politica internazionale, Roma, Laterza.

Yus Ramos, F. (2010). Ciberpragmática 2.0. El uso del lenguaje en Internet, Barcelona, Ariel.

Zappavigna, M. (2011). “Ambient affiliation: a linguistic perspective on Twitter”, New Media Society, 13 (5), pp. 788-806.

Recibido 3 junio 2013 Aceptado: 12 diciembre 2013 Revisado: 30 diciembre 2013

Publicado: 31 diciembre 2013 Actualizado: 17 enero 2014 